\title{
Developing and Cultivating
Our Precious Resources
}

Throughout human history, the wealth of a nation has always been measured by its natural resources, i.e. materials. Wars and even world wars have been fought in order to gain a neighbor's natural resources. The strength of a nation can also be measured by its ability to convert these natural resources into useful goods and technologies. Materials have played such an important role in our history that we have even named epochs after them, e.g., the Stone Age, the Bronze Age, the Iron Age, etc.

Since World War II we have begun to see much greater emphasis on developing new technology through better and novel materials such as plastics, semiconductors, and ceramics, to name just a few. The economic wealth of countries has clearly shifted toward measuring their technological skills and quality products.

\section{The wealth of a nation can be measured by its skilled human resources.}

In fact, though, the wealth of a nation can, in certain terms, be measured by its skilled human resources. During the last three decades the so-called "high tech" of the world, covering such areas as computers, space vehicles, solid-state electronics and fiber optics, has clearly been an outcome of breakthroughs in the science and engineering of novel and high quality materials. It requires a tremendous amount of human resource to develop these high tech materials. On the other hand, developing and cultivating human resources requires a long-term commitment investment ( 10 to 15 years, from high school to college to graduate school) from government, industry, and educational institutions.

Will there be enough skilled human resources in materials science and engineering 5 or 10 years down the road to help sustain the economic wealth of the United States?

I believe those of us on the academic side have a clear picture of what is coming down the pipeline. I believe what I am sampling at Northwestern University in the Department of Materials Science and Engineering is similar to what comparable U.S. universities are finding:

1. We need a much larger undergraduate enrollment;

2. We are competing with other top universities for a very small pool of high quality graduate students;

3. A large number of graduate applicants who want to study electronic materials are from outside the United States;

4. Most U.S. graduate students do not want to have a teaching job after they receive their PhDs (they see how hard their advisors have to work to get research funding);

5. It also follows then that there will be a shortage of high quality teachers; and

6. Most universities do not have the necessary hardware to train students in advanced technology.

How can the Materials Research Society and other materials-related societies play a significant role in developing and cultivating this important national resource?

I believe MRS, through its membership, is in a unique position to help. The Materials Research Society can serve as a channel, a bridge or a coordinator among government, industries, and the universities. We are, in fact, already serving in this capacity on a small scale through the work of our committees and programs:

1. Our Academic Affairs Committee is conducting university activities on campuses through various MRS-sponsored programs. They are also providing information on materials for high school students.

2. The Publications Committee is preparing video tapes for educational purposes. We also have Joumal of Materials Research archives as well as the MRS BULLETIN to provide updated research information.

3 . The Awards Committee is trying to encourage and enlarge the MRS student recognition program with more awards, etc.

4. The Continuing Education Committee has an extensive range of up-to-date short course programs for students as well as their teachers.

5. Our job placement program helps the students to find job opportunities.

6. MRS is currently developing more ad-
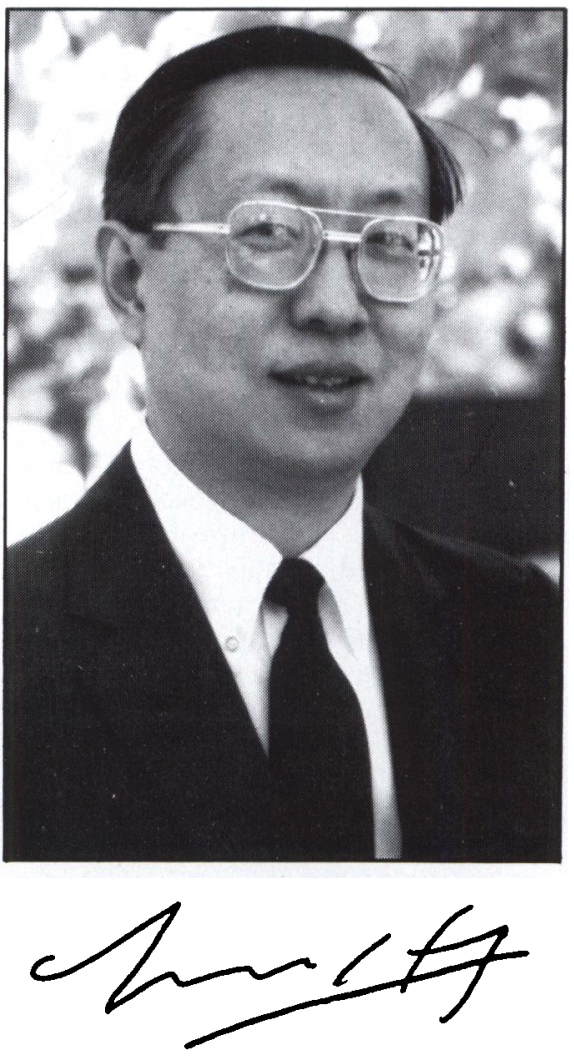

vanced means of disseminating technical information relating to materials.

7. Through its External Affairs Committee, the Materials Research Society will be in a unique position to advise the government and industries on materials issues relating to the latest technological breakthroughs, competitiveness, longrange planning, human resources, and more.

8. Through our international activities MRS is cultivating friendship with materials-related societies worldwide. These relationships will not only help improve the exchange of scientific information but also give insight to develop human resources for materials research and technology.

The success of these programs clearly depends on the cooperation and sponsorship of the government, industries, and universities. MRS looks forward to serving the materials community at large. By working together I am sure we will not only increase our precious human resources, but sustain U.S. competitiveness in the world marketplace.

R.P.H. Chang 